\title{
Analysis on the Predicament and Way out of the Current Financing of Chinese Small and Medium Enterprises in the "New Normal" Economy
}

\author{
Hongzhen Liu \\ Management school, Wuhan University of Science and Technology \\ Wuhan, china 430081 \\ liuhongzhen@wust.edu.cn
}

Keywords: New Normal; Small and Medium-Sized Enterprises; Financing; Credit; Predicament

\begin{abstract}
The economic development has entered a new normal, and the development of SMEs in China has emerged new features. Financing problems are more complex. In order to solve the financing problems of SMEs, this paper makes deep analysis on the current major financing difficulties faced by the Chinese small and medium-sized enterprises, through theoretical analysis and data demonstration, respectively from the macro and micro, internal and external different sides. On this basis, the paper further puts forward a series of specific countermeasures and suggestions such as strengthing the new normal thinking, improving the overall quality of enterprises, smoothing communication channels, formulating preferential policies, improving the multi-level financing system ect. It provides a way to effectively solve the financing problems of small and medium-sized enterprises under the new normal economy..
\end{abstract}

\section{Introduction}

SME is the largest and most innovative enterprise group in China. It has an irreplaceable role in promoting economic growth, furthering innovation, increasing tax revenue, creating jobs and improving people's livelihood and so on. Data shows that in recent years, the number of SMEs accounts for more than $99 \%$ of the total number of domestic market entities, created more than $60 \%$ per cent of the gross domestic product, contributed over 50\% tax, provided $80 \%$ Per cent of new urban jobs, completed over $60 \%$ patents, more than $70 \%$ technical innovation, $80 \%$ per cent of new product development. Due to the long term influence under the traditional system, the financing problem has not been solved, problems over the years become the "bottleneck" of the survival and development of SMEs. As China's economic development has entered a new norm, financing problems are more prominent, it have become important factors which affect SME development and trend of China's economy.

\section{Main Difficulties Faced By Chinese Small and Medium Enterprises in Current Financing Process}

At the new normal period, new pressure is put on small and medium enterprises. At present, China's economic development has entered into a new normal phrase. During this phrase there appears some dramatic features such as slowdown in economic growth, structural optimization, and power conversion ect. These significant characteristics have brought unprecedented pressure to the production and management of SMEs. First of all, due to slowdown in economic growth, the pressure on production and operation of SMEs enterprises increases. However the large companies, using their own advantages, transfer much stress to the small and medium enterprises by squeezing down the raw materials purchase prices, accelerating capital returns, occupying the market share, which lead to further increasing of the pressure on production and operation in SMEs. Secondly, the deep adjustment of the economic structure sets up a ' magic spell' to those industries with surplus production capacity of small and medium enterprises, and some are even washed out in the game directly. Third, with the change of momentum, part of the extensive SME lost its advantages, and the new advantages are not easy to form during short period. Therefore they 
eventually sink into a quagmire. In short, for SMEs, the new normal is overall and long-term positive. But because of its many deficiencies, some SMEs have to put up with the temporary pain of torture resulted from the new normal period, and some would even face the survival crisis. Official statistics show that China's SMEs development index (SMEDI) following the drop from the high level of a few years ago has maintained a trend of low stabilization in the past three years. It is expected that this trend will continue (see the following figure).

\section{figure 1: Chinese SMEs Development Index through year 2011-2016 (Quarterly)}

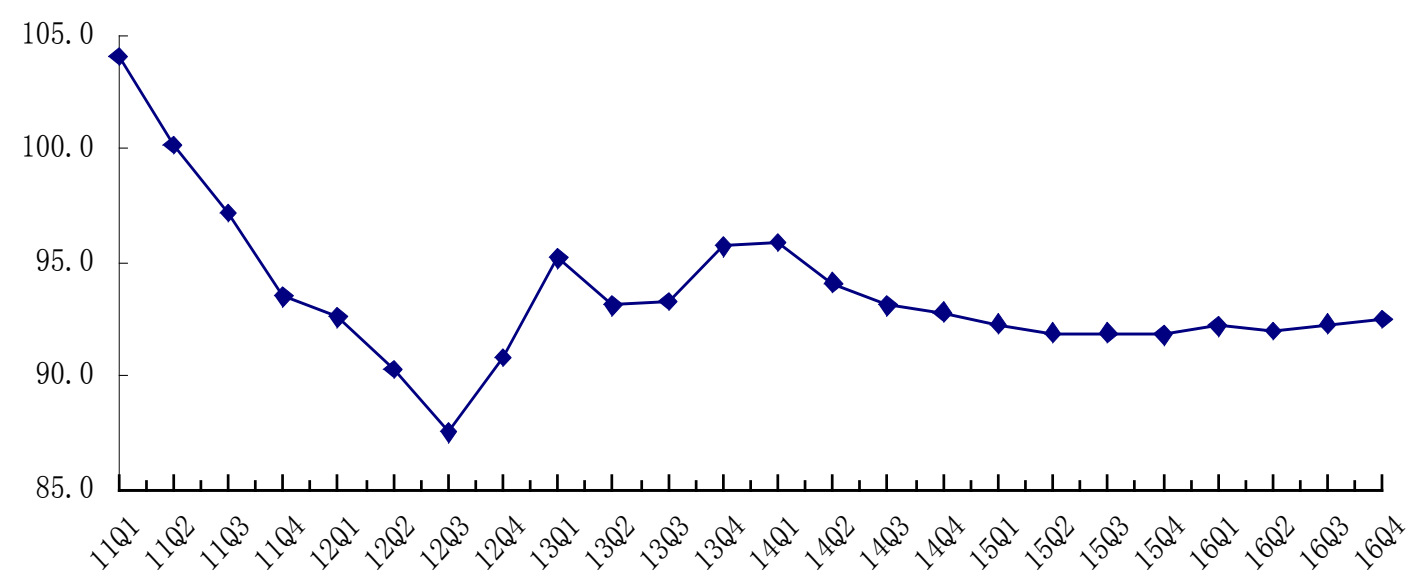

\begin{tabular}{|c|c|c|c|c|c|c|c|c|c|c|c|c|}
\hline Year & \multicolumn{4}{|c|}{2011} & \multicolumn{5}{c|}{2013} \\
\hline Quarter & Q1 & Q2 & Q3 & Q4 & Q1 & Q2 & Q3 & Q4 & Q1 & Q2 & Q3 & Q4 \\
\hline Index & 104.1 & 100.2 & 97.2 & 93.5 & 92.6 & 90.3 & 87.5 & 90.8 & 95.2 & 93.1 & 93.3 & 95.7 \\
\hline Year & \multicolumn{9}{|c|}{2014} & \multicolumn{8}{|c|}{2015} \\
\hline Quarter & Q1 & Q2 & Q3 & Q4 & Q1 & Q2 & Q3 & Q4 & Q1 & Q2 & Q3 & Q4 \\
\hline Index & 95.9 & 94.1 & 93.1 & 92.8 & 92.3 & 91.9 & 91.9 & 91.8 & 92.2 & 92.0 & 92.3 & 92.5 \\
\hline
\end{tabular}

SME's congenital weaknesses have determined its disadvantage of financing. Compared with big enterprise, China's SMEs have many congenital weaknesses as follows: (1) generally small business scale and single products structure; (2) overall backward production technology and low technology content ; (3) fuzzy development strategy, blindly pursuit to be big and strong, not prominent core business and lack of market positioning and business features; (4) serious family type management phenomenon, company governance structure is not perfect, poor quality of management team and lack of knowledge of modern business management; (5) low quality financial personnel, imperfect financial system, financial mismanagement, the untrue and incomplete report, many companies cannot provide accurate and complete financial information to banks, and so on. These congenital weaknesses constraint the development forthcoming strength of SME seriously and makes it difficult to connect with bank credit standards effectively, let alone finance from stock market .

The situation of direct financing of small and medium enterprises is not optimistic. In recent years, with the deepening of reform of China's financial market, especially the successful implementation of the Small-medium Size board and start up board , the "New Three Board" range-extending, as well as small and medium enterprises set bond, collection notes, trust financing be carried out in a way, there are many tools for direct financing of small and medium enterprises. However, due to China's capital market is far from perfect and underdeveloped, review cycles for IPO is unpredictability, leading SME listing approval of direct financing lags far behind the growing financing demand. Meanwhile, the direct financing functionality is limited for new three board. Non-listed companies cann't issue shares, only allowing directional capital increase, furthermore it has cumbersome procedures. For new Three Board-listed SME the threshold is still relatively high, the number of listed finance companies can be described as "rare." For this, I 
selected several index, there is a comparison these index on China's securities market in 2015 year (see the following table), and finally come to three conclusions: firstly the number of market listing for small and medium enterprise market is far less than the main Board, the total number of national enterprises and SMEs is $99 \%$, it is obviously inconsistent with the main status of SME. Secondly, copmared with the main boardmarket, the index of average amount of financing and average value of the SME are relatively low which reflect the situation is unsatisfactory, the average enterprise turnover index for the SMEboard and start up board is high which reflect the market trading is relatively active (this may be relate to the China stock currently speculation atmosphere too thick ). Thirdly most of the new three board index are low except the index of number of listing copmanies which reflect the new three board is not actively traded in the market, financing is extremely poor.

Table: 2015 Basic Situation of China's Securities Market Comparison

\begin{tabular}{c|c|c|c|c}
\hline & Main board & SME & Start up & $\begin{array}{c}\text { The new } \\
\text { three board }\end{array}$ \\
\hline $\begin{array}{c}\text { Number of listed } \\
\text { companies (units) }\end{array}$ & 2,828 & 776 & 492 & 5,129 \\
$\begin{array}{c}\text { Turnover (billion) } \\
\text { Average Enterprise } \\
\text { turnover (billion) }\end{array}$ & $1,268,582.78$ & $497,556.18$ & $285,352.81$ & $1,910.62$ \\
$\begin{array}{c}\text { Financing amount } \\
\text { (billion) }\end{array}$ & $15,078.85$ & $3,228.36$ & $1,569.15$ & $1,216.17$ \\
$\begin{array}{c}\text { Average financing } \\
\text { amount (billion) } \\
\text { Market capitalization } \\
\text { (billion) }\end{array}$ & 5.33 & 4.16 & 3.19 & 0.24 \\
$\begin{array}{c}\text { Average Enterprise } \\
\text { market value (billion) }\end{array}$ & 165.49 & $103,950.47$ & $55,916.25$ & $24,584.42$ \\
\hline
\end{tabular}

Indirect financing is becoming more difficult. Over the years, bank loans are the main source of financing of SMEs. After the international financial crisis, the Chinese banks emphasis on risk control, tight traditional lending, SME financing have given rise to new situations: one is that the right of approval of bank loans is over centralized. The operating banks which engage in field survey, and master first-hand information of grass-roots business have no loan approval right, and the banks which away from enterprise have the right of loan approval, but they are not familiar with enterprise situation, only focuses on financial statements, many "live situation" and "soft information" are hard to be passed to approval personnel and get adopted, this can effect approval success rate, also cause bank approval link increased, and approval time elongated, even if loan is approved, opportunities are missed. Second, loans threshold is high. Banks generally requires three years of performance, leading to many new starts, production enterprises is excluded from the doors of bank credit. Normally banks only secured mortgage loans to SMEs, and only accept the land, real estate mortgage, while most SMEs are small businesses, fewer assets that can be pledged as security for bank loan, it is difficult to meet the Bank's loan conditions. Third, there is too much emphasis on risk management and implementation of accountability. Comparing to the big enterprises and big projects, SME lending risk management costs are high, Bank staff are fear of difficulty, unwilling marketing small business loans. Four, development concept needs to be changed. Banking market competition relative not full, and China special of interest rate control policy, Bank institutions can easily get stable market share and interest spread income, so most of the banks are keen to the long-term loan, large loan in amount and, and loan concentration. Extensive management, homogeneous competition, relying on the phenomenon of spread are more common. Actively cultivate the market, explore customers, promote innovation awareness are not strong. For SMEs and other emerging businesses do not want to do and can not do.

The role of small and medium enterprises guarantee corporation did not give full play. Most of the credit guarantee institutions have strong administrative color, the registered capital in place rate 
is low, operation is not standard. At the same time as the guarantee fund amount is small, risk responsibility is too low, banks are reluctant to put too much credit risk on guarantee corporation, this leads to the difficult to choose the guarantee corporation cooperative bank. The majority of small and medium enterprises credit guarantee corporation capital is less, the ability to guarantee is weak, furthermore the approval process is cumbersome. Due to the poor strength of guarantee corporation, the bank does not believe that the strength of guarantee corporation, a considerable number of the guarantee corporation's business is not saturate, security amplification is limited.

\section{The Countermeasures to Solve the Financing Problems of Small and Medium Sized Enterprises in China}

To firmly establish the new normal thinking. Understanding the new normal, adapting to the new normal, leading the new normal, it is the trend for the China's economic development in the current and future, and it is also the development logic of small and medium enterprises. It can be said that using the new normal thinking to guide the work of SMEs is an important prerequisite for solving the financing problems of SMEs. To take effective measures to promote, including all levels of government and relevant departments, the whole society to deepen understanding, change idea, consciously recognize the new normal, to adapt to the new normal, leading the new norm, to guide the work of small and medium-sized enterprises with the new normal thinking. All of small and medium-sized enterprises should change the way of thinking, understanding and accurately grasping the connotation and characteristics and practice requirements of the economic development of the new normal, five development ideas, the supply side structural reform, Working on the birth of endogenous motivation. For the enterprise development direction, objectives, tasks and measures, they must conduct a comprehensive and systematic analysis and evaluation, and make timely adjustment, seize the opportunity of economic transformation and upgrading, to achieve the corner overtaking, and catching up.

Striving to improve the overall quality of small and medium enterprises. To improve the overall quality of small and medium enterprises is the necessary prerequisite to solve the financing difficulty of SMEs. From their own point of view, only if focusing on the long term, tpracticing skill, perfecting system, regulating management, it can promote the sustained and healthy development of enterprises, and adapt to the profitability of capital and get more external funding. The key is to highlight the core business, foster strategic advantage, strengthen corporate governance, strengthen credit consciousness, improve financial transparency, establish a good relationship between banks and enterprises. From the government perspective, governments at all levels and relevant departments should actively organize the small and medium-sized enterprise managers and financial personnel to conduct the training work in the form of flexible and diverse contents, to improve the quality of service, strive to enhance the management of small and medium-sized enterprises, to achieve standardized management. The national industrial policy information and industry information should be released and transfered timely to the majority of SMEs, to promote its correct decision-making, scientific development.

Establishing channels of communication between banks and enterprises, increasing information transparency. Firstly, it is necessary to do a good job in the national SME information collection and collation as soon as possible to improve the SME information database and provide search services. On the one hand, we can strengthen credit consciousness of the enterprise, cultivate the enterprise credit self-discipline mechanism, on the other hand, it also provides an open and transparent information platform for the bank to serve the small and medium-sized enterprises better. The second is to further improve the financial services sector linkage mechanism and cooperation platform between enterprises and banks, jointly attended by relevant government departments and financial institutions, discuss the problems of financial services of small and medium sized enterprises regularly, to provide capital demand intention for those SMES which have potential development, the integrity of the compliance management to financial institutions, to nurture and support the small and medium-sized enterprises develop and grow. The third is to establish and improve the SME loan business statistics and default notification system, strengthen the restraint 
mechanism, strengthen risk warning.

Coming up with the preferential policies to promote the development of SMEs. It is necessary to promote the development of small and medium-sized enterprises to the height of the national strategy, to guide banks and the guarantee corporation to improve awareness, and actively carry out SME lending business. Governments at all levels should focus on capital injection to increase financial support of the guarantee corporation for small and medium-sized enterprises through the financial sector, improve guarantee corporation magnification for small and medium-sized enterprise, and further simplify procedures. It is necessary to guide banks to actively arrange a certain proportion of credit loans to support the development of small and medium enterprises, appropriate decentralization of small business loan approval authority, effectively shorten the approval time, improve the efficiency of approval. At the same time, the government should formulate the measures for assessment of reward of small and medium-sized enterprises loans, a certain proportion of all banks and guarantee corporation carrying out the loans to small and medium sized enterprises shall be rewarded, or set up small business loan risk compensation fund, for banks and guarantee corporation which carry out small and medium-sized enterprise which have loan business losses will get a certain proportion of compensation. For the guarantee corporation which carry out the loan guarantee and the banks which get the revenue from the disposal of non-performing loans, the tax authorities may implement exemption policy from business tax. Administrative fees related to business lending business, real estate and land and other relevant departments should be given appropriate relief, and set the maximum amount of policy assessment, notary fees, and effectively reduce the cost of mortgage.

Improving the multi-level financing system of SMEs. The first measure is to further increase the small and medium-sized enterprises listed counseling efforts, and actively organize and recommend the small and medium-sized enterprises to finance through the Shenzhen SME board and start up board, and actively guide the small and medium-sized enterprises to issue private bond through the Shanghai Stock Exchange for SMEs. Through the establishment of a sound working mechanism to promote the normalization of listed companies, the government should put the emphasis on the promotion of SME direct financing channels, form the development patterns of training a batch, counseling a batch and listing a batch. The second measure is to accelerate the construction of perfect function, reasonable division of labor, property rights and effective supervision of the financial service system of small and medium-sized enterprises, the focus is to accelerate the cultivation of new rural financial institutions and the pace of development, make the city commercial banks bigger and stronger, and actively support the development of the guarantee corporation, financial leasing companies and small loan company . The third measure is with the gradual expansion of three new board market, it is necessary to establish and improve the relevant system as the focus, to ensure the healthy development of three new board.

\section{Summary}

Chinese economic development has entered a new norm, and the financing of small and medium-sized enterprises are facing new pressures brought by the new normal. By their internal and external reasons caused by long-term problems, financing is not optimistic whether direct or indirect, and it has become an important impact factor in the development of economy and the trend of Chinese economy. Therefore, we should adhere to the new normal thinking to guide the work of small and medium-sized enterprises, improve the overall quality of small and medium-sized enterprises, smooth communication channels between banks and enterprises, formulate preferential fiscal and taxation, credit, fees and other policies to promote the development of small and medium-sized enterprises. It is also necessary and important to perfect the financing system of small and medium sized enterprises from the aspects of multi-level, implement comprehensive measures to explore the ways to solve the financing way out of the problem of small and medium-sized enterprises. 


\section{References}

[1] Gu Lei, Zheng Hejuan, Zhang Xiaofang. Studies on the Financing Problems of Small and Medium-sized Enterprises: From the Perspective of Industrial Cluster Development in Western China [M]. Beijing: Economic and Management Press ( 2014 )

[2] Wuxiao, Qian Yubo. Small and Medium Enterprise Financing Case and Practice Guidelines [M]. Beijing: China Machine Press (2015)

[3] Kong Lingxue, Zhang Wenliang, Wang Jing. Sloving financing difficulties: Small and Medium Enterprise Financing Channels. Policy and Practice [M]. China Market Press ( 2016 )

[4] Liu Hongzhen, Xu Shaoming. Advice on the financing difficulties of small and medium enterprises in Hubei province. Guide to Business2012(20):149-150

[5] Zhang Zhanbing. The trend characteristics of the new economic norm in China and the policy orientation. Journal of Chinese Academy Of Governance2015(1):15-20

[6] Lv Jingsong. Thinking about the financing difficulties and high cost of SMEs. Journal of Financial Research 2015(11):115-123

[7] Yang Qian, Du Wenqiang. Discussion and Analysis on the Financing Problems of Small and Medium Enterprises under the new economics norm, [J]. Modern Business Trade Industry 2015,36(14):17-18

[8] Huang jia. Research on the small and medium enterprise financing difficulties and countermeasure. China Journal of Commerce2016(10):72-74

[9] Yan Bailiang, Xia Xiufang. Evaluation and analysis on financial risk of Chinese Small and medium enterprise in the new economic norm. China Business2016(15):110-112

[10]Bai Jie. Study on Chinese small and medium enterprise financing difficulties and countermeasure. Management and Technolosy of SME 2016(25):44-45 